\title{
Fish eyes and brain as primary targets for mercury accumulation - A new insight on environmental risk assessment
}

\author{
Patrícia Pereira a,b,c,d,*, Joana Raimundo b,e, Olinda Araújo ${ }^{\text {b }}$, João Canário ${ }^{\mathrm{f}}$, \\ Armando Almeida ${ }^{\mathrm{c}, \mathrm{d}}$, Mário Pacheco ${ }^{\mathrm{a}}$ \\ a Department of Biology and CESAM, University of Aveiro, 3810-193 Aveiro, Portugal \\ b IPMA - Portuguese Institute for the Sea and Atmosphere, Av. Brasília, 1449-006 Lisbon, Portugal \\ ${ }^{c}$ Life and Health Sciences Research Institute (ICVS), School of Health Sciences, University of Minho, Campus de Gualtar, 4710-057 Braga, Portugal \\ d ICVS/3Bs, PT Government Associated Laboratory, Braga/Guimarães, Portugal \\ e Interdisciplinary Centre of Marine and Environmental Research (CIIMAR/CIMAR), University of Porto, 4050-123 Porto, Portugal \\ ${ }^{\mathrm{f}}$ Centro de Química Estrutural, Instituto Superior Técnico, Universidade de Lisboa, Av. Rovisco Pais, 1049-001 Lisboa, Portugal
}

\section{H I G H L I G H T S}

- The propensity of fish brain, eye wall and lens to $\mathrm{Hg}$ accumulation was evaluated.

- Brain, eye wall and lens faithfully reflected water and sediment $\mathrm{Hg}$ contamination.

- Fish brain and eyes are key target organs in environmental health assessment.

- MeHg was preferentially accumulated in the three neurosensory structures than $\mathrm{iHg}$.

- Fish lens exhibited a higher $\mathrm{Hg}$ retention capacity than brain and eye wall.

\section{A R T I C L E I N F O}

\section{Article history:}

Received 21 March 2014

Received in revised form 2 July 2014

Accepted 3 July 2014

Available online 21 July 2014

Editor: Frank Riget

\section{Keywords:}

Methylmercury

Inorganic mercury

Bioaccumulation

Neurosensory structures

Fish

Environmental contaminant biomonitoring

\begin{abstract}
A B S T R A C T
Fish eyes and brain are highly susceptible to environmental Hg exposure but this issue is still scarcely investigated, mainly regarding methylmercury ( $\mathrm{MeHg}$ ) accumulation. Yet, Hg levels in fish lens have not been previously examined under field conditions. Total $\mathrm{Hg}(\mathrm{tHg}), \mathrm{MeHg}$ and inorganic $\mathrm{Hg}(\mathrm{iHg})$ levels were assessed in the brain, eye wall and lens of the golden grey mullet (Liza aurata) from an $\mathrm{Hg}$ contaminated area, both in winter and summer, together with water and sediment levels. Sampling was performed at Aveiro lagoon (Portugal) where a confined area (LAR) is severely contaminated by Hg. Fish brain, eye wall and lens accumulated higher levels of tHg, $\mathrm{MeHg}$ and iHg at LAR than the reference site, reflecting faithfully environmental spatial differences. The brain and eye wall responded also to the winter-summer changes found in water and sediment, accumulating higher levels of $\mathrm{MeHg}$ (and tHg) in winter. Contrarily, lens was unable to reflect seasonal changes, probably due to its composition and structural stability over time. The three neurosensory structures accumulated preferentially $\mathrm{MeHg}$ than $\mathrm{iHg}$ (MeHg was higher than $77 \%$ of tHg). Lens exhibited a higher retention capacity of $\mathrm{MeHg}$ (mean around $1 \mu \mathrm{g} \mathrm{g}^{-1}$ at LAR), accumulating higher levels than the other two tissues. Interestingly, MeHg and iHg levels were significantly correlated for the brain and eye wall but poorly associated within the two analysed eye components. The high levels of MeHg found in the brain, eye wall and lens could compromise their functions and this needs further research.
\end{abstract}

(C) 2014 Elsevier B.V. All rights reserved.

\section{Introduction}

The nervous system, mainly its sensory organs and pathways, exerts control over a wide array of physiological and behavioural responses, and so, exposure to neurotoxicants has the capacity to affect organism

\footnotetext{
* Corresponding author at: Department of Biology and CESAM, University of Aveiro, 3810-193 Aveiro, Portugal. Tel.: + 35121 3027172; fax: + 351213015948

E-mail address: ppereira@ipma.pt (P. Pereira).
}

fitness. Mercury ( $\mathrm{Hg}$ ) compounds (including methylmercury - MeHg) have triggered major concerns in terms of environmental and human health. Though $\mathrm{Hg}$ is recognised as a pernicious, persistent and ubiquitous contaminant in natural waters, including estuarine and marine environments, the assessment of its potential to induce neuronal and sensory dysfunctions in aquatic animals is an almost unexplored issue.

Fish are key components of the trophic chains, also playing an important role signalling water pollution, once they react with great sensitivity to changes in the aquatic systems (Van der Oost et al., 
2003; Guilherme et al., 2008; Mieiro et al., 2010). Keeping this in view, numerous works quantified $\mathrm{Hg}$ (including $\mathrm{MeHg}$ ) in fish organs (e.g. liver, gills) as a mean to evaluate environmental quality, trying to establish causal relationships with fish health (e.g. Zorita et al., 2008; Pereira et al., 2010; Mieiro et al., 2011). Generally, the brain and the eyes have been disregarded in those studies. Unexpectedly, total mercury levels in the brain reflected better than metabolic organs (such as the liver and kidney) the concentrations reported in the environment (Mieiro et al., 2009). These authors also found that fish brain can have an important role in biomagnification processes, pointing to its relevance in environmental risk assessment. Recently, fish eyes revealed to faithfully reflect water and sediment contamination by metals (Pereira et al., 2013). However, to the best of our knowledge, no other field studies have correlated metal levels in fish brain or eyes with contamination levels in the environment.

In mammals, the brain has been demonstrated as a primary target for $\mathrm{Hg}$ compounds, namely $\mathrm{MeHg}$, and neurological dysfunctions have been widely studied in humans and rodents, being reported the occurrence of intellectual impairments, irritability and fine motor alterations (Aschner et al., 2007; Stringari et al., 2008; Farina et al., 2013). Identical to mammals, fish brain is highly susceptible to environmental $\mathrm{Hg}$ exposure, as demonstrated by the few available articles reporting neurodegenerative damage and disturbances on sensory processing (Baatrup et al., 1990) as well as behaviour changes (Berntssen et al., 2003). This is in line with the assertion that both organic and inorganic forms of $\mathrm{Hg}$ could be damaging agents to fish central nervous system (Berntssen et al., 2003).

The eye is a key sensory organ that collects and focuses images, transforming them into neural signals. The fish eye has a wide surface area in continuous contact with the external medium and thus could be a relevant uptake route of $\mathrm{Hg}$. Exposure of zebrafish larvae to waterborne MeHg revealed that this metal form was preferentially accumulated in the eyes, specifically in the outer layer of the lens (Korbas et al., 2013). Interestingly, MeHg levels in the lens increased even after exposure, indicating that $\mathrm{MeHg}$ is accumulated in this eye component also through redistribution from other tissues (Korbas et al., 2013). These results clearly show that $\mathrm{Hg}$ targets the eyes and particularly the lens. The direct MeHg action on eye sensory cells may be partly responsible for visual disturbances (Korbas et al., 2008, 2013). As a result of the unique morphology and stability of eye lens over the organism's life, it has been suggested that lens could potentially offer a historical record of $\mathrm{Hg}$ exposures affecting fish throughout its lifetime (Korbas et al., 2008).

The promising results obtained by Korbas et al. (2008, 2010, 2012, 2013) with fish brain and eyes after MeHg exposure and the relevance of these organs on fish physiology pointed to their potential in environmental health assessment. Hence, the present work aimed to study $\mathrm{Hg}$ accumulation (including $\mathrm{MeHg}$ ) in the brain, eye wall and lens in the golden grey mullet (Liza aurata) inhabiting an $\mathrm{Hg}$ contaminated system, coupled with water and sediment contamination. It was also intended to clarify tissue specificities and the influence of winter-summer variations of environmental conditions on accumulated $\mathrm{Hg}$ levels. This is the first study that investigated $\mathrm{Hg}$ levels in the eyes (including lens) in wild fish.

\section{Material and methods}

\subsection{Study area characterization}

The Aveiro lagoon ( $47 \mathrm{~km}^{2}$ of maximum surface area) is a coastal ecosystem located on the northwest coast of Portugal (Fig. 1). It has an inner and enclosed area known as Laranjo basin (a shallow area with $2 \mathrm{~km}^{2}$ ) that has received $\mathrm{Hg}$ effluents from a chloro-alkali plant during around five decades (1950-1994). High levels of $\mathrm{Hg}$ are still stored in sediments (Coelho et al., 2005) and could be found in the biota (Guilherme et al., 2008; Mieiro et al., 2010). Due to the absence

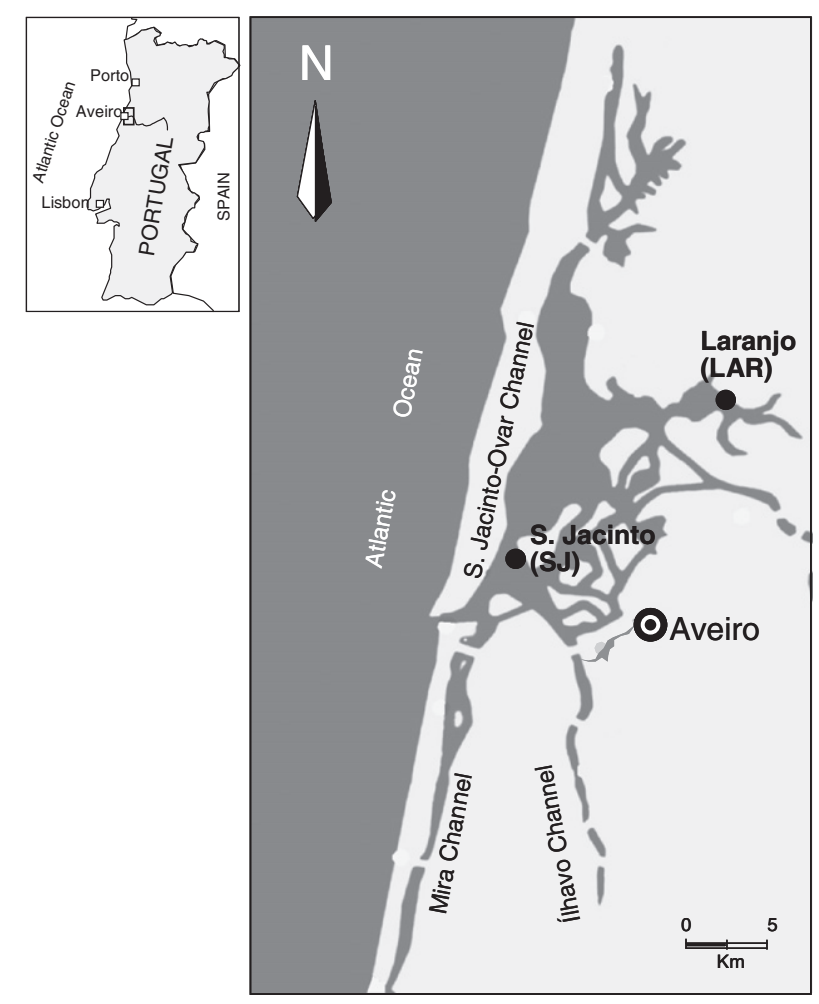

Fig. 1. Location of the sampling sites at Aveiro lagoon (Portugal): São Jacinto (SJ) $\left(40^{\circ} 41^{\prime}\right.$ $\left.00^{\prime \prime} \mathrm{N}, 8^{\circ} 42^{\prime} 44^{\prime \prime} \mathrm{W}\right)$; Laranjo (LAR) (4043'28.98" N, $\left.8^{\circ} 37^{\prime} 35.80^{\prime \prime} \mathrm{W}\right)$.

of other important sources of contaminants, Laranjo basin is considered a "field laboratory", offering a unique opportunity to assess mercury toxicity under realistic conditions (Guilherme et al., 2008). São Jacinto is located near the lagoon entrance, about $10 \mathrm{~km}$ from Laranjo basin. In previous studies, São Jacinto area was selected as a reference for comparison proposes, since it was considered unpolluted including in terms of Hg (Guilherme et al., 2008; Mieiro et al., 2010).

\subsection{Sampling}

Two surveys were carried out at Aveiro lagoon, in winter (February 2013) and summer (June 2013), during low-tide, and juveniles of the golden grey mullet (Liza aurata) were collected $(\mathrm{n}=10)$ using a traditional beach-seine net. Two sampling sites were selected taking into account previous ecotoxicological studies (Guilherme et al., 2008; Mieiro et al., 2010) (Fig. 1): Laranjo (LAR) in the most contaminated area; São Jacinto (SJ) as the reference site. In winter at LAR and SJ, fish total length was $12.4 \pm 0.63$ and $11.9 \pm 0.15 \mathrm{~cm}$, respectively, while in summer it was $13.6 \pm 2.1$ and $16.5 \pm 2.1 \mathrm{~cm}$, respectively. Immediately after catching, fish were anaesthetized, sacrificed and properly bled, and then the brain and eyes were removed. The eyes were carefully washed with distilled water and gentle rubbing (to remove adherent particles) and dissected for lens removal. The remaining components of the eye, encompassing the eye wall (retina, sclera, cornea, ciliar body, etc.), chambers' content (vitreous and aqueous humours) and other small structures (hereafter collectively called "eye wall", to simplify) were also stored. In the field, the brain, eye wall and lens were instantly frozen in liquid nitrogen. In the laboratory, samples were preserved at $-80{ }^{\circ} \mathrm{C}$ until further processing for $\mathrm{Hg}$ determinations.

Sub-surface water (at $0.2 \mathrm{~m}$ depth) was sampled in triplicates to polypropylene bottles for the determination of total $\mathrm{Hg}(\mathrm{tHg})$ and $\mathrm{MeHg}$ in the dissolved fraction of water column. At the same depth, temperature, salinity and dissolved oxygen were measured in situ in triplicates with an YSI 650 meter (Yellow Springs, USA). Surface 
sediments (approximately $2 \mathrm{~cm}$ depth) were collected in the two sites for $\mathrm{tHg}$ and $\mathrm{MeHg}$ determinations.

\subsection{Analytical procedures}

Total dissolved mercury was determined following U.S.EPA method 1631 (U.S.EPA, 2002). Briefly, water samples were preserved by the addition of $0.5 \% \mathrm{BrCl}$ until analyses (less than one week after collection). The samples were then analysed by cold-vapour atomic fluorescence spectrometry (CV-AFS) with a PSA model Merlin 10.023 equipped with a detector PSA model 10.003 using $\mathrm{SnCl}_{2}$ reduction. BCR-579 reference material was used to control the accuracy of the procedure.

Methylmercury in water samples was determined following U.S.EPA method 1630 (U.S.EPA, 2001) by distillation of $50 \mathrm{~mL}$ sub-samples, after addition of $1 \% \mathrm{C}_{5} \mathrm{H}_{9} \mathrm{NS}_{2} \cdot \mathrm{NH}_{3}$ as a complexing agent. Mercury was ethylated with $\mathrm{NaB}\left(\mathrm{C}_{2} \mathrm{H}_{5}\right)_{4}$, purged with argon, collected on Tenax ${ }^{\mathrm{TM}}$ traps, separated with a GC, thermally desorbed to $\mathrm{Hg}(0)$ for detection of MeHg with a Brooks Rand Model III CV-AFS. All batches of samples analysed for $\mathrm{MeHg}$ included at least one method replicate, and at least three analytical replicates of certified reference material (SQC-1238) (Sigma-Aldrich RTC).

Sediment samples were analysed for $\mathrm{tHg}$ by atomic absorption spectrometry (AAS) with thermal decomposition following gold amalgamation in an Hg analyser (AMA) LECO 254 (Costley et al., 2000). Methylmercury was determined in dry sediments by alkaline digestion $(\mathrm{KOH} / \mathrm{MeOH})$, organic extraction with dichloromethane (DCM) preconcentration in aqueous sulphide solution, back-extraction into DCM and quantification by GC-AFS in a Agilent Chromatograph coupled with a pyroliser unit and a PSA fluorescence detector (Canário et al., 2004). Recoveries and the possible $\mathrm{MeHg}$ artefact formation were evaluated by spiking several samples with $\mathrm{Hg}$ (II) and $\mathrm{MeHg}$ standard solutions with different concentrations. Recoveries varied between 97 and $103 \%$ and no artefact $\mathrm{MeHg}$ formation was observed during our procedure. Precision of $\mathrm{Hg}$ analysis, expressed as relative standard deviation (RSD) of 4 replicate samples, was less than $4 \%(\mathrm{p}<0.05)$. Certified reference materials (MESS-2, IAEA-405 and BCR-580) were used to ensure the accuracy of the procedure. Levels of $\mathrm{tHg}$ and $\mathrm{MeHg}$ obtained in the reference materials were consistent within the ranges of certified values.

The brain, eye wall and lens samples were firstly lyophilised and homogenised. Samples were then analysed for tHg as previously described for sediment. For MeHg analysis a modified Westöö (1967) and Armstrong et al. (1999) methodology was used. Briefly, approximately $2 \mathrm{~mL}$ of Milli-Q water and $3 \mathrm{~mL}$ of $\mathrm{KOH}(6 \mathrm{M})$ solution were added to $200 \mathrm{mg}$ of dried sample. The mixture was shaken for $2 \mathrm{~h}$ and then 3 $\mathrm{mL}$ of $\mathrm{HCl}(6 \mathrm{M})$ and $4 \mathrm{~mL}$ of a $\mathrm{KBr} / \mathrm{CuSO}_{4}(3: 1)$ solution were added. After $10 \mathrm{~min}$ of shaking, $5 \mathrm{~mL}$ of DCM was then added, the mixture centrifuged and finally the organic phase separated. A slight sulphide solution $(\approx 0.06 \mathrm{mM}$ ) was used to extract $\mathrm{MeHg}$ from the organic phase and then $\mathrm{MeHg}$ was back extracted to DCM. Methylmercury in DCM was quantified by GC-AFS using the chromatographic equipment described above. Again, the possible MeHg artefact formation was evaluated by spiking several samples with $\mathrm{Hg}$ (II) and $\mathrm{MeHg}$ standard solutions of different concentrations. Recoveries varied between 92 and 103\% and no artefact MeHg formation was observed. For all the analysis, precision expressed as the relative standard deviation of 3 replicate samples, was less than $2 \%(\mathrm{p}<0.05)$. Certified reference materials (DORM-3, DOLT-4) were used to ensure the accuracy of the procedures.

A crude estimation of the total inorganic mercury (iHg) concentrations in the brain, eye wall and lens was done by subtracting thg levels by the corresponding $\mathrm{MeHg}$ concentrations. For this estimation it was assumed that MeHg is the only organic mercury compound that is bioaccumulated in fish (Zhang and Adeloju, 2012).

\subsection{Data analysis}

Statistical software (Statistica 6.0) was used for statistical analyses. All data were first tested for normality (Shapiro-Wilk test) and homogeneity of variance (Levene's test) to meet statistical demands. Twoway ANOVA was performed to compare sampling sites or seasons and to test the influence of the combined effect of site and season on $\mathrm{tHg}$ and $\mathrm{MeHg}$ accumulation levels. The Tukey test was applied for posthoc comparison. Differences between means were considered significant when $\mathrm{p}<0.05$. The following correlations were statistically tested using Spearman correlation analysis - the brain vs. eye wall, the brain vs. lens and the eye wall vs. lens - for $\mathrm{tHg}$ and $\mathrm{MeHg}$ concentrations. Correlations were considered significant for $\mathrm{p}<0.05$.

\section{Results}

\subsection{Water and sediment characteristics}

Water temperature was higher at LAR and SJ in summer than in winter, while salinity was lower at LAR than SJ, particularly in winter (Table 1). Dissolved oxygen was around 100\% but undersaturation was recorded at LAR in summer. LAR presented higher levels of total dissolved $\mathrm{Hg}$ and $\mathrm{MeHg}$ in water than SJ, being these differences accentuated in winter. In this season, an enhanced proportion of $\mathrm{Hg}$ was present in the MeHg form relatively to summer at LAR (Table 1).

Surface sediments from LAR exhibited higher levels of tHg and $\mathrm{MeHg}$ than SJ both in winter and summer (Table 2). Seasonal differences were recorded for tHg and $\mathrm{MeHg}$ in sediments, showing levels one order of magnitude higher in winter than in summer at LAR. The percentage of $\mathrm{Hg}$ in the MeHg form was maxima at LAR in summer.

\subsection{Mercury levels in the brain, eye wall and lens}

The brain of fish from LAR showed significantly higher accumulation of tHg, MeHg and iHg than SJ in both seasons (Fig. 2). No statistical differences were found between sites for the percentage of $\mathrm{MeHg}$ with respect to tHg in summer and winter. Differences between the two surveys were found for $\mathrm{tHg}$ and $\mathrm{MeHg}$ with higher levels in winter than in summer at LAR. The percentage of MeHg was significantly higher in winter than in summer in both sampling sites, while no seasonal differences were found for iHg.

The inter-site differences found in the eye wall for $\mathrm{tHg}, \mathrm{MeHg}$ and $\mathrm{iHg}$ were similar to those described for the brain, with significantly higher levels being recorded at LAR than SJ (Fig. 3). The percentage of

Table 1

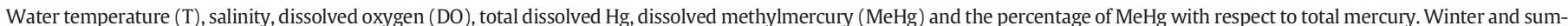
mer data, measured at low-tide, are presented for São Jacinto (SJ) and Laranjo (LAR) at Aveiro lagoon. Mean and associated standard deviations are presented. n.d. not determined.

\begin{tabular}{|c|c|c|c|c|c|c|c|}
\hline Season & Site & $\begin{array}{l}\mathrm{T} \\
\left({ }^{\circ} \mathrm{C}\right)\end{array}$ & Salinity & $\begin{array}{l}\text { DO } \\
(\%)\end{array}$ & $\begin{array}{l}\text { Total Hg } \\
\left(\text { ng L L }^{-1}\right)\end{array}$ & $\begin{array}{l}\text { MeHg } \\
\left(\mathrm{ng} \mathrm{L}^{-1}\right)\end{array}$ & $\begin{array}{l}\mathrm{MeHg} \\
(\%)\end{array}$ \\
\hline \multirow[t]{2}{*}{ Winter } & SJ & $13 \pm 0.15$ & $31 \pm 0.13$ & $94 \pm 0.50$ & $<0.1$ & $<0.01$ & n.d. \\
\hline & LAR & $12 \pm 0.00$ & $4.9 \pm 0.01$ & $87 \pm 0.84$ & $4.4 \pm 0.90$ & $1.0 \pm 0.24$ & $23 \pm 2.4$ \\
\hline \multirow[t]{2}{*}{ Summer } & SJ & $18 \pm 0.12$ & $33 \pm 0.11$ & $102 \pm 1.9$ & $1.0 \pm 0.02$ & $0.016 \pm 0.007$ & $1.4 \pm 0.79$ \\
\hline & LAR & $18 \pm 0.05$ & $21 \pm 0.07$ & $65 \pm 0.50$ & $1.5 \pm 0.77$ & $0.040 \pm 0.008$ & $3.0 \pm 0.83$ \\
\hline
\end{tabular}


Table 2

Total $\mathrm{Hg}$, methylmercury ( $\mathrm{MeHg}$ ) and the percentage of $\mathrm{MeHg}$ with respect to total $\mathrm{Hg}$ in surface sediment. Winter and summer data are presented for São Jacinto (SJ) and Laranjo (LAR) at Aveiro lagoon. Mean and associated standard deviations are presented.

\begin{tabular}{llcll}
\hline Season & Site & $\begin{array}{l}\text { Total Hg } \\
\left(\mu \mathrm{g} \mathrm{g}^{-1}\right)\end{array}$ & $\begin{array}{l}\text { MeHg } \\
\left(\mu \mathrm{g} \mathrm{g}^{-1}\right)\end{array}$ & $\begin{array}{l}\mathrm{MeHg} \\
(\%)\end{array}$ \\
\hline \multirow{2}{*}{ Winter } & SJ & $0.021 \pm 0.010$ & 0.00005 & 0.38 \\
& LAR & $2.9 \pm 0.37$ & 0.029 & 0.95 \\
Summer & SJ & $0.025 \pm 0.005$ & $0.0001 \pm 0.00002$ & $0.44 \pm 0.04$ \\
& LAR & $0.44 \pm 0.25$ & $0.008 \pm 0.003$ & $1.9 \pm 0.42$ \\
\hline
\end{tabular}

$\mathrm{MeHg}$ exhibited the same spatial variation trend. Eye wall showed significantly higher levels of $\mathrm{tHg}, \mathrm{MeHg}$ and its percentage in winter than in summer at LAR. MeHg percentage was also significantly higher in winter than in summer in the eye wall from SJ. No seasonal differences were found for $\mathrm{iHg}$ at both sites.

Lens of fish from LAR presented significantly higher levels of tHg, $\mathrm{MeHg}$ and $\mathrm{iHg}$ than SJ, both in winter and summer (Fig. 4), while no spatial differences were recorded for the percentage of MeHg. Levels of tHg, MeHg (or its percentage) and $\mathrm{iHg}$ in lens were similar in winter and summer.

Lens accumulated higher levels of $\mathrm{tHg}$, followed by the brain and the eye wall with means ranging from 0.25 to $1.09 \mu \mathrm{g} \mathrm{g}^{-1}, 0.11-0.61 \mu \mathrm{g} \mathrm{g}^{-1}$ and $0.05-0.30 \mu \mathrm{g} \mathrm{g}^{-1}$, respectively. A similar trend was recorded for MeHg levels: $0.25-1.0 \mu \mathrm{g} \mathrm{g}^{-1}$ in the lens, $0.09-0.53 \mu \mathrm{g} \mathrm{g}^{-1}$ in the brain and $0.04-0.28 \mu \mathrm{g} \mathrm{g}^{-1}$ in the eye wall. Lens presented also the highest proportion of $\mathrm{Hg}$ in the $\mathrm{MeHg}$ form ( $\geq 96 \%)$, followed by the eye wall ( $\geq 83 \%$ ) and brain $(\geq 77 \%)$. On the contrary, the brain showed slightly higher mean values of $\mathrm{iHg}\left(0.01-0.07 \mu \mathrm{g} \mathrm{g}^{-1}\right)$ than the eye wall and lens (0.01-0.03 $\mu \mathrm{g} \mathrm{g}^{-1}$ and $0.01-0.04 \mu \mathrm{g} \mathrm{g}^{-1}$, respectively).

Significant interactions between site and season were recorded for tHg and MeHg in the brain and eye wall (Table 3) but no significant interactions were obtained for the percentage of $\mathrm{MeHg}$ and iHg. No significant interactions were found between site and season for tHg, $\mathrm{MeHg}$ (including its percentage) and $\mathrm{iHg}$ in the lens.

3.3. Relationships between $\mathrm{MeHg}$ and inorganic $\mathrm{Hg}$ in the brain, eye wall and lens and correlations between tissues

Fig. 5 presents the relationships between $\mathrm{MeHg}$ and iHg levels $\left(\mu \mathrm{g} \mathrm{g}^{-1}\right)$ for the brain, eye wall and lens. A significant, positive and linear relationship $\left(r^{2}=0.64\right)$ was obtained for the brain, while no significant associations were found for the eye wall and lens.

All the analysed tissues were significantly correlated for $\mathrm{MeHg}$, whereas $\mathrm{iHg}$ was only correlated in the case of the brain vs. eye wall (Fig. 6). Stronger correlations were obtained for MeHg levels in the brain vs. eye wall $\left(r^{2}=0.93\right)$, whereas significant but poorer relationships were found in the brain vs. lens $\left(\mathrm{r}^{2}=0.50\right)$ and in the eye wall vs. lens $\left(r^{2}=0.45\right)$.

\section{Discussion}

4.1. Mercury levels in the brain, eye wall and lens and association with environmental availability

LAR exhibited a higher availability of total dissolved $\mathrm{Hg}(\mathrm{tHg})$ and $\mathrm{MeHg}$ than SJ in both seasons, which is in line with spatial differences previously observed (Mieiro et al., 2011). Differences between the two sampling sites regarding $\mathrm{Hg}$ in water were accentuated in winter relatively to summer ( 44 and 100 times higher for $\mathrm{tHg}$ and $\mathrm{MeHg}$ in winter, respectively while values only doubled in summer). This is probably due to the higher re-suspension of $\mathrm{Hg}$ enriched sediments at Laranjo basin in winter. In fact, sediments from LAR exhibited also higher levels of $\mathrm{Hg}$ in winter than in summer ( $\mathrm{tHg}$ was almost 7 times higher in winter than in summer, while MeHg enhanced 4 times). The spatial contamination trend recorded in water was also found in the sediments with higher
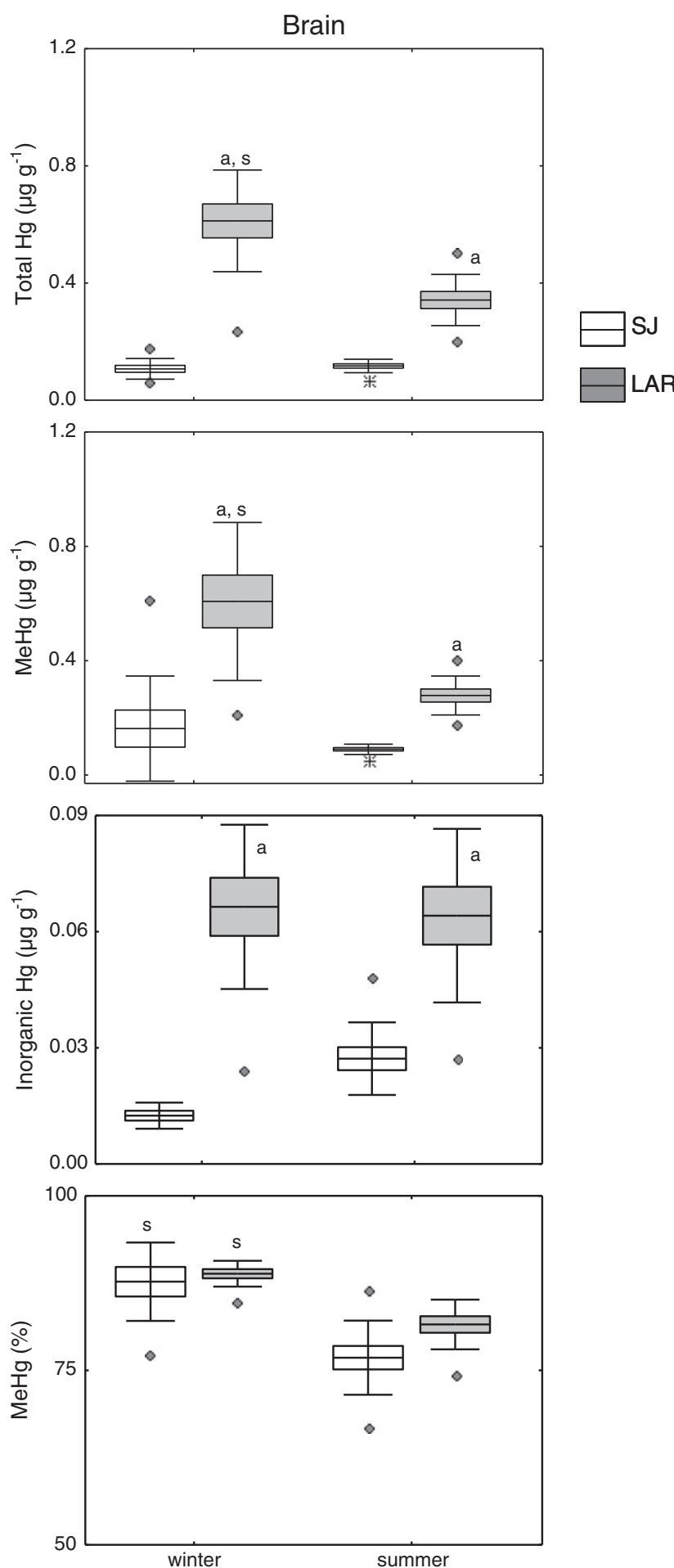

Fig. 2. Total $\mathrm{Hg}$, $\mathrm{MeHg}$, inorganic $\mathrm{Hg}$ ( $\mu \mathrm{g} \mathrm{g}^{-1}$, dry weight) and \% of $\mathrm{MeHg}$ (in relation with total $\mathrm{Hg}$ ) in the brain of L. aurata captured in winter and summer in Laranjo (LAR) and São Jacinto (SJ) at Aveiro lagoon. Mean, standard deviation, standard error, outliers (O) and extreme values $(※)$ are presented. $a$ indicates significant differences between sites (within the same season) and $s$ denotes seasonal significant differences (within the same site).

levels of tHg and MeHg recorded at LAR than SJ. It was previously documented that LAR sediments are heavily contaminated by $\mathrm{Hg}$ and the depth variation reflects the industrial discharge evolution during the last decades (Ramalhosa et al., 2001).

The brain of fish from the contaminated area (LAR) accumulated higher levels of $\mathrm{MeHg}$ and $\mathrm{iHg}$ (and consequently $\mathrm{tHg}$ ) than at the reference site, clearly evidencing a mercury exposure. $\mathrm{MeHg}$ in the brain 
Eye wall
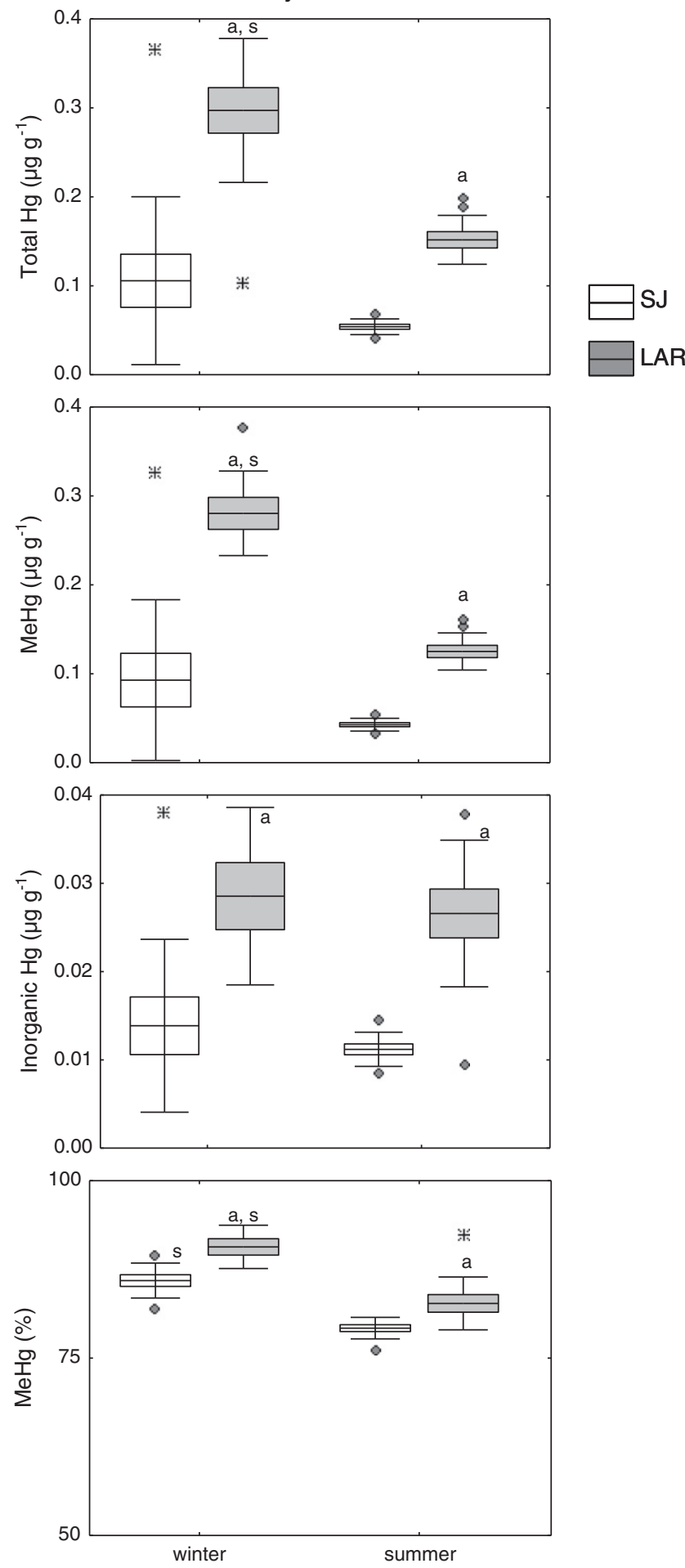

Fig. 3. Total $\mathrm{Hg}$, MeHg, inorganic $\mathrm{Hg}\left(\mu \mathrm{g} \mathrm{g}^{-1}\right.$, dry weight) and \% of $\mathrm{MeHg}$ (in relation with total $\mathrm{Hg}$ ) in the eye wall of $L$. aurata captured in winter and summer in Laranjo (LAR) and São Jacinto (SJ) at Aveiro lagoon. Mean, standard deviation, standard error, outliers (O) and extreme values $(※)$ are presented. $a$ indicates significant differences between sites (within the same season) and $s$ denotes seasonal significant differences (within the same site).

(consistent with tHg) reflected inter-site differences recorded in water and sediment. These results are in line with previous findings of Mieiro et al. (2009) who demonstrated that $L$. aurata brain was able to reflect environmental variations of $\mathrm{Hg}$ in a field study performed at Aveiro lagoon. That work only determined tHg in L. aurata brain while the current
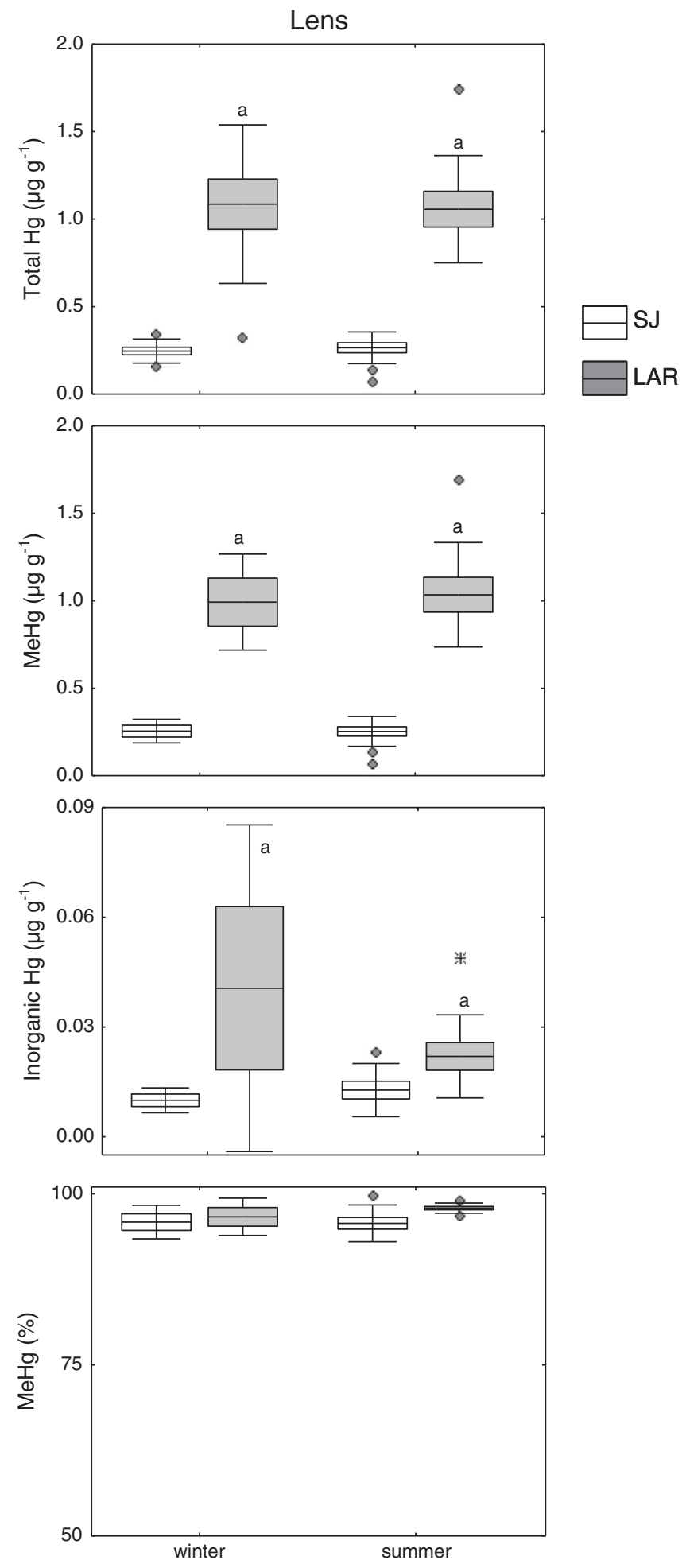

Fig. 4. Total $\mathrm{Hg}$, MeHg, inorganic $\mathrm{Hg}$ ( $\mu \mathrm{g} \mathrm{g}^{-1}$, dry weight) and \% of $\mathrm{MeHg}$ (in relation with total $\mathrm{Hg}$ ) in the lens of L. aurata captured in winter and summer in Laranjo (LAR) and São Jacinto (SJ) at Aveiro lagoon. Mean, standard deviation, standard error, outliers (○) and extreme values $(※)$ are presented. $a$ indicates significant differences between sites (within the same season).

one contributed with identical conclusions for $\mathrm{MeHg}$, one of the most toxic forms of $\mathrm{Hg}$. Lipid solubility of $\mathrm{Hg}$ compounds promotes its accumulation in lipid-rich compartments such as the brain (Guzzi and Porta, 2008). Additionally, $\mathrm{MeHg}$ (and specifically the thiol-bound $\mathrm{MeHg}$ ) is similar enough to endogenous substrates for the active transporters 
Table 3

Two-way ANOVA analysis testing the effect of site, season and interaction (site $\times$ season) on the concentrations of total $\mathrm{Hg}$, $\mathrm{MeHg}$, percentage of $\mathrm{MeHg}$ and inorganic $\mathrm{Hg}$ in the brain, eye wall and lens of $L$. aurata. The $\mathrm{F}$ and $\mathrm{p}$ values are given for each variable. n.s. - not significant.

\begin{tabular}{|c|c|c|c|c|c|c|c|}
\hline \multirow[t]{2}{*}{ Organ } & \multirow{2}{*}{$\begin{array}{l}\text { Dependent } \\
\text { variable }\end{array}$} & \multicolumn{2}{|l|}{ Site } & \multicolumn{2}{|l|}{ Season } & \multicolumn{2}{|c|}{ Site $\times$ season } \\
\hline & & $\mathrm{F}$ & $\mathrm{p}$ & $\mathrm{F}$ & $\mathrm{p}$ & $\mathrm{F}$ & $\mathrm{p}$ \\
\hline \multirow[t]{4}{*}{ Brain } & Total Hg & 128.12 & $<0.001$ & 16.28 & $<0.001$ & 18.83 & $<0.001$ \\
\hline & $\mathrm{MeHg}$ & 32.28 & $<0.001$ & 12.99 & $<0.001$ & 5.31 & $<0.05$ \\
\hline & $\% \mathrm{MeHg}$ & 3.84 & n.s. & 36.32 & $<0.001$ & 1.44 & n.s. \\
\hline & Inorganic $\mathrm{Hg}$ & 64.37 & $<0.001$ & 1.20 & n.s. & 2.25 & n.s. \\
\hline \multirow[t]{4}{*}{ Eye wall } & Total $\mathrm{Hg}$ & 48.81 & $<0.001$ & 22.71 & $<0.001$ & 5.13 & $<0.05$ \\
\hline & $\mathrm{MeHg}$ & 58.55 & $<0.001$ & 33.95 & $<0.001$ & 8.90 & $<0.05$ \\
\hline & $\% \mathrm{MeHg}$ & 19.10 & $<0.001$ & 60.75 & $<0.001$ & 0.44 & n.s. \\
\hline & Inorganic $\mathrm{Hg}$ & 30.77 & $<0.001$ & 0.73 & n.s. & 0.017 & n.s. \\
\hline \multirow[t]{4}{*}{ Lens } & Total Hg & 83.53 & $<0.001$ & 0.0031 & n.s. & 0.072 & n.s. \\
\hline & $\mathrm{MeHg}$ & 73.13 & $<0.001$ & 0.051 & n.s. & 0.062 & n.s. \\
\hline & $\% \mathrm{MeHg}$ & 2.62 & n.s. & 0.35 & n.s. & 0.62 & n.s. \\
\hline & Inorganic $\mathrm{Hg}$ & 6.48 & $<0.05$ & 1.02 & n.s. & 1.87 & n.s. \\
\hline
\end{tabular}

regulating the cellular uptake and efflux of molecules, promoting its higher accumulation in tissues (Korbas et al., 2012). Mercury accumulation in mammals' brain is well reported but it is scarcely documented in fish (Rouleau et al., 1999; Berntssen et al., 2003; Mieiro et al., 2010, 2011), particularly in what concerns to the mechanisms by which $\mathrm{Hg}$
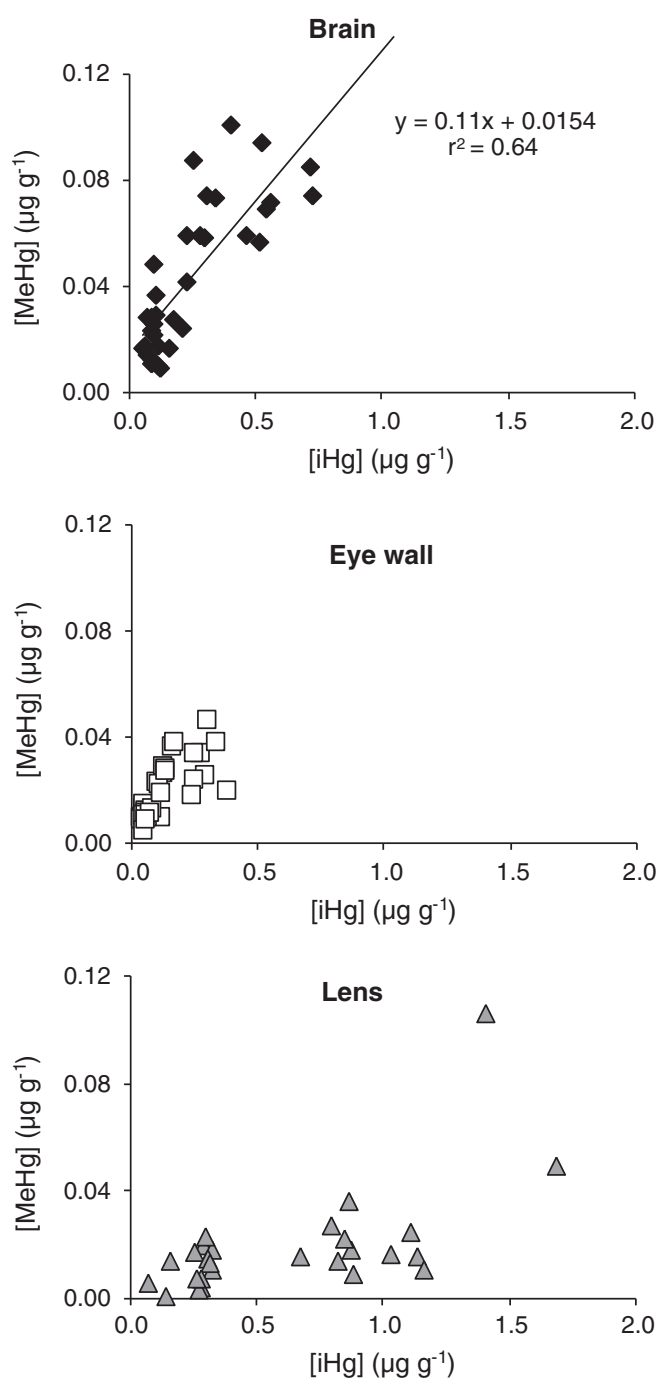

Fig. 5. Relationships between concentrations of $\mathrm{MeHg}$ and inorganic $\mathrm{Hg}(\mathrm{iHg})\left(\mu \mathrm{g} \mathrm{g}{ }^{-1}\right.$, dry weight) for the brain, eye wall and lens of $L$. aurata captured in Aveiro lagoon. Winter and summer data are plotted together. reaches the brain. It has been demonstrated that MeHg passes through the blood-brain barrier (BBB) and reaches either cellular or nuclear components, causing irreversible damage to the nervous system in human (Zheng et al., 2003) and fish (Boening, 2000). Contrarily, Rouleau et al. (1999) found that fish BBB is impervious to iHg in plasma, suggesting that waterborne $\mathrm{iHg}$ is taken up by water-exposed receptor cells of sensory nerves and subsequently transferred toward the brain by axonal transport.

Fish eyes are in permanent and direct contact with dissolved metals and those linked with re-suspended sediment particles. In fact, the significantly higher accumulation of $\mathrm{MeHg}$ and $\mathrm{iHg}$ (and likewise $\mathrm{tHg}$ ) in fish eye wall (all ocular components except lens) measured at LAR in winter and summer indicated an enhanced uptake. Inorganic $\mathrm{Hg}$ and $\mathrm{MeHg}$ levels in the eye wall were around 2 to 3 times higher at LAR than SJ in both seasons. These results are in agreement with a previous study that found higher levels of trace elements in fish eyes from a contaminated area of the Tagus estuary (Portugal) (Pereira et al., 2013). Fish lens from LAR also exhibited an enhanced accumulation of $\mathrm{MeHg}$ and $\mathrm{iHg}$ (in line with $\mathrm{tHg}$ ) in relation to fish from Korbas et al. (2013) investigated the uptake and accumulation of $\mathrm{MeHg}$ in zebrafish larvae and found the highest levels in the secondary lens fibers underlying the lens epithelium. It was also reported that $\mathrm{MeHg}$ targets photoreceptors which are directly involved in visual perception (Korbas et al., 2013).

The brain and eye wall of $L$. aurata accumulated higher levels of $\mathrm{MeHg}$ (and tHg) in winter than in summer at LAR. This is in agreement with the higher environmental availability of $\mathrm{Hg}$ (including in the $\mathrm{MeHg}$ form) in winter relatively to summer. Besides that, the influence of water salinity on $\mathrm{Hg}$ accumulation should be considered since values at LAR were 4-fold lower in winter than those recorded in summer. It was previously reported that tHg accumulation in crabs from Aveiro lagoon was favoured by low salinity (Pereira et al., 2006), consistent with the current data on fish. Mercury is able to form strong inorganic complexes with chloride at saline and oxygen-rich waters (Conaway et al., 2003). In line, current data revealed a higher percentage of dissolved $\mathrm{MeHg}$ at LAR in winter (when salinity was lower) than in summer. Since MeHg counterparts are highly accumulated in fish comparing to chloride $\mathrm{Hg}$ forms (Korbas et al., 2012), water salinity could indirectly influence the accumulated $\mathrm{Hg}$ levels. Elevated water temperature can also increase metal accumulation associated with the higher metabolism of ectothermic organisms (Sokolova and Lannig, 2008). Current data revealed a higher accumulation in winter relatively to summer but only at LAR. This suggests a minor role of temperature on $\mathrm{Hg}$ accumulation. Despite the higher winter availability of $\mathrm{MeHg}$ (and tHg) in water and sediment from LAR, lens did not reveal that seasonal variation as occurred for the brain and eye wall. Lens presented levels of $\mathrm{MeHg}$ and its percentage, as well as iHg, identical in winter and summer both at SJ and LAR.

\subsection{Tissue-specific accumulation - considerations on mercury toxicokinetics}

The three neurosensory structures accumulated $\mathrm{Hg}$ preferentially in the $\mathrm{MeHg}$ form. A minimum percentage of $\mathrm{MeHg}$ was found in the brain (77\%), while in the lens compartment more than $96 \%$ of tHg was in the $\mathrm{MeHg}$ form. In fact, the estimated levels of $\mathrm{iHg}$ were very low, suggesting a preferential uptake of the MeHg counterpart, as previously documented for invertebrates (e.g. Tsui and Wang, 2004; Raimundo et al., 2010) and fish (e.g. Burger and Gochfeld, 2006). It was previously demonstrated that MeHg load in fish brain was around 200 times higher than for iHg (Oliveira Ribeiro et al., 2000). Current levels pointed to a lower difference in the accumulation of both $\mathrm{Hg}$ chemical forms in L. aurata brain, with levels of MeHg being only 3 to 13 times higher than $\mathrm{iHg}$. MeHg is an $\mathrm{Hg}$ form very stable in the brain, even if it can eventually change to HgSe (Korbas et al., 2013).

To the best of our knowledge, this is the first quantitative study reporting $\mathrm{MeHg}$ and $\mathrm{iHg}$ levels in fish eyes (with the separation of lens) and data pointed to unprecedented conclusions in wild fish. Lens 

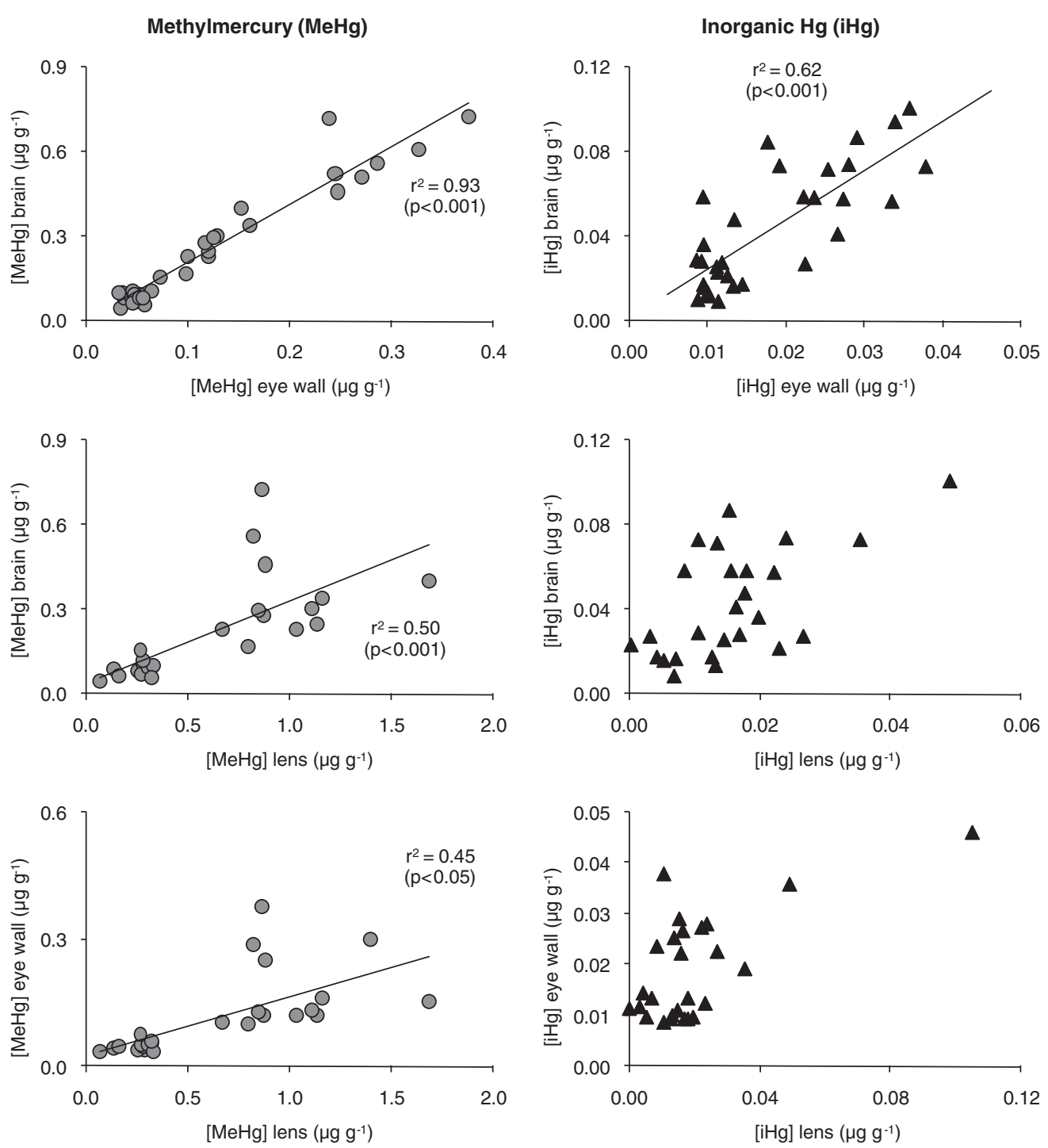

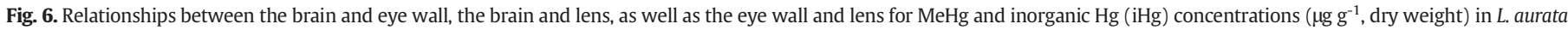
captured at Aveiro lagoon. Winter and summer data are plotted together.

exhibited the highest accumulated levels of $\mathrm{MeHg}$ (and likewise tHg) followed by the brain and eye wall. MeHg levels in the lens doubled relatively to the brain whereas in relation to eye wall were 4 to 6 times higher. A higher proportion of $\mathrm{Hg}$ in the $\mathrm{MeHg}$ form was also detected in the lens relatively to the brain or eye wall of $L$. aurata. In agreement, Korbas et al. (2013) found higher levels of MeHg in the secondary lens fibres (directly underlying the lens epithelium) relatively to the brain and optic nerve in zebrafish larvae. This is probably related with a higher proportion of protein material in the lens comparatively to the brain and eye wall, since the particular affinity of $\mathrm{MeHg}$ to thiol groups of proteins has been demonstrated (Leaner and Mason, 2004). Lens is the site of particularly high protein production (named as crystallins) and deposition (Korbas et al., 2010).

Lower accumulation of $\mathrm{MeHg}$ in the brain relatively to the other tissues was accompanied by slightly higher iHg levels, particularly at LAR (ranges of iHg mean values were: 0.064-0.066 $\mu \mathrm{g} \mathrm{g}^{-1}, 0.027-$ $0.029 \mu \mathrm{g} \mathrm{g}^{-1}$ and $0.022-0.041 \mu \mathrm{g} \mathrm{g}^{-1}$, for the brain, eye wall and lens, respectively). This could be partially related with a demethylation capacity since it was described that some of the MeHg in the brain may be converted into $\mathrm{iHg}$ (Ercal et al., 2001). The relationship found between MeHg and iHg accumulation in the brain $\left(r^{2}=0.64\right)$ (not found in the other tissues) is in line with the association between the two $\mathrm{Hg}$ forms, reinforcing the hypothesis of demethylation activity in the brain. Whether the conversion of MeHg into iHg plays a neuroprotective role is a matter that requires further investigation. On one hand, it has been demonstrated that iHg could be excreted 3-fold faster than $\mathrm{MeHg}$ in fish (Trudel and Rasmussen, 1997). On the other hand, $\mathrm{iHg}$ showed to be more potent than MeHg in inhibiting glutamine synthetase activity in cortical astrocytes (Allen et al., 2001). In the light of the findings of Allen et al. (2001), the iHg levels currently found in L. aurata brain are not negligible in terms of neurotoxic hazard. Inorganic $\mathrm{Hg}$ accumulated in L. aurata brain in a minimum of $11 \%$ (mean value in relation with $\mathrm{MeHg}$ ) while the values estimated by Ercal et al. (2001) were lower, ranging between 3 and 6\%. Thus, demethylation should not be assumed as the only mechanism promoting $\mathrm{iHg}$ accumulation in this organ. It should be also considered the axonal transport of iHg and/or its (re)distribution from other tissues including the blood.

Levels of $\mathrm{MeHg}$ and $\mathrm{iHg}$ found in the brain, eye wall and lens are also influenced by organs' anatomic location that determines the exposure route and distribution. The transport of $\mathrm{MeHg}$ via blood both to the brain and the eye wall is likely to occur. In fact, both tissues are protected by the epithelial barriers (blood-brain and blood-retinal barriers), which strictly regulate the transport of molecules from the bloodstream. Thiol-bound MeHg (specifically MeHg cysteineate, the most dominant form of MeHg in vivo) can penetrate these barriers (Korbas et al., 2013). The similar pathways of MeHg for the brain and eye wall 
could explain the high correlations found between both tissues for its accumulation. On the contrary, $\mathrm{iHg}$ was only weekly correlated in the case of the brain vs. eye wall, confirming its lower mobility in fish body. The different toxicokinetics of $\mathrm{MeHg}$ and $\mathrm{iHg}$ was corroborated by the absence of statistical correlations between the two chemical forms in the eye wall and lens.

Liza aurata lens exhibited considerably higher levels of MeHg than the other ocular tissues, as aforementioned. The high affinity of $\mathrm{MeHg}$ for lens in relation with the rest of eye is probably explained by their distinct tissue structure and composition. It is not known at the present why the eye lens accumulates such high levels of MeHg but it could be partially related with its major protein nature, because there is a high affinity of MeHg to thiol groups of proteins (Leaner and Mason, 2004). Considering that eyes are in contact with water and suspended particles, $\mathrm{Hg}$ can target lens after its direct uptake by the eyes' surface. However, poorer correlations were found between the eye wall and lens for $\mathrm{MeHg}$ (comparatively with the brain vs. eye and the brain vs. lens) and no associations were found between the eye wall and lens for iHg. Additionally, it should be hypothesised that $\mathrm{Hg}$ may reach the eyes by axonal transport (via optic nerve), similarly to what was proposed to the brain (Rouleau et al., 1999), and then translocated to the lens. It was previously demonstrated that $\mathrm{MeHg}$ levels continue to increase in the lens after fish removal from the exposure solutions due to redistribution from other organs like the liver and brain (Korbas et al., 2010).

The lens is an avascular structure surrounded by an elastic collagen coat (Lemire et al., 2010). In adult fish like in mammals, the lens is separated from the eye wall by the aqueous and vitreous humours, being linked only by a ligament/muscle connection. Keeping in view this pseudo-isolation of lens from the remaining eye compartments, their high accumulation ability could be regarded as a physiological defence mechanism of fish against environmental exposure to $\mathrm{Hg}$, namely MeHg. This could be particularly important in the protection of more vulnerable eye components and ultimately of fish vision. Despite that, considering the high accumulated levels of $\mathrm{MeHg}$ in lens and its elevated toxicity, it should be pondered that fish could develop ocular anomalies in lens, such as cataracts or opacity, as previously reported in humans exposed to $\mathrm{Hg}$ (Lemire et al., 2010).

\subsection{Insight on environmental risk assessment}

The selection of the best tissue to signal environmental spatial differences is difficult on the basis of current data. In fact, all the three tissues (the brain, eye wall and lens) were able to detect the higher contamination at LAR than SJ. Moreover, environmental health assessment should be performed in distinct temporal periods due to changes on availability of contaminants and organisms' physiology. From the seasonal point of view, lens is the least responsive tissue. Lens did not mirror the higher environmental levels of total dissolved $\mathrm{Hg}$ and $\mathrm{MeHg}$ in winter at LAR, while the brain and eye wall signallized those winter-summer differences.

The distinct spatial and temporal patterns of $\mathrm{MeHg}$ and $\mathrm{iHg}$ accumulation in lens could be indicative that this compartment is able to reflect marked environmental differences like those imposed by different locations, whereas subtle temporal changes could not be identified by this eye component. This is probably due to lens composition and structural constancy over time, without cell or non-cellular component turnover. Thus, metal load is cumulative along time, reflecting a sequence of exposures. Taking into account fish mobility, this constraint becomes more relevant, probably avoiding that lens could reflect recent exposures. On the contrary, lens could offer a historical record of $\mathrm{Hg}$ exposures affecting fish through its lifetime due to its unique stability (Dove and Kingsford, 1998; Korbas et al., 2008).

From the analytical perspective, all the three analysed tissues displayed relatively high $\mathrm{Hg}$ levels (mainly $\mathrm{MeHg}$ ) and a sufficient amount of mass for analysis. The brain and eyes are interesting due to the possibility of $\mathrm{Hg}$ determinations in different compartments (like lens in the eyes or different brain areas) and the quantification of distinct organic counterparts (e.g. MeHg).

\section{Conclusions}

Results of this work provided these main findings:

- Fish eyes and brain are primary target organs in environmental health assessment since they faithfully reflect water and sediment $\mathrm{Hg}$ contamination. The brain, eye wall and lens accumulated $\mathrm{Hg}$ preferentially in the MeHg form. Thus, it is important to evaluate changes in these organs/tissues at structural and functional levels in order to examine in what extent accumulated Hg could compromise neurosensory processes.

- Within fish eyes, current data revealed unprecedented conclusions for lens under field research. Lens exhibited higher MeHg accumulation than the brain and the remaining eyes' components.

- The MeHg levels were highly related between the brain and eye wall pointing out similarities on the distribution from bloodstream, as well as on the storage. On the contrary, MeHg levels were poorly associated within eyes' components, presumably due to the distinct chemical nature of lens and the remaining eye structures.

- All the three tissues were able to distinguish contrasting spatial differences but only the brain and eye wall reflected winter-summer changes, probably due to the high retention capacity of lens. This information on tissue-specificities could be very useful for environmental health assessment and subsequent management and policy.

\section{Acknowledgements}

Patrícia Pereira (SFRH/BPD/69563/2010) and Joana Raimundo (SFRH/BPD/91498/2012) benefit from Post-doctoral grants supported by "Fundação para a Ciência e a Tecnologia" (FCT). This work as been supported by the Research project financed by FCT PTDC/AAG-REC/ 2488/2012 (NEUTOXMER - Neurotoxicity of mercury in fish and association with morphofunctional brain alterations and behavior shifts), as well as by the Centre for Environmental and Marine Studies (CESAM). Authors are also grateful to Sofia Guilherme for the support in sampling campaigns.

\section{References}

Allen JW, Mutkus LA, Aschner M. Mercuric chloride, but not methylmercury, inhibits glutamine synthetase activity in primary cultures of cortical astrocytes. Brain Res 2001; 891(1-2):148-57.

Armstrong HEL, Corns WT, Stockwell PB, O'Connor G, Ebdon L, Evans EH. Comparison of AFS and ICP-MS detection coupled with gas chromatography for the determination of methylmercury in marine samples. Anal Chim Acta 1999;9(390):253.

Aschner M, Syversen T, Souza DO, Rocha JBT, Farina M. Involvement of glutamate and reactive oxygen species in methylmercury neurotoxicity. Braz J Med Biol Res 2007;40: 285-91.

Baatrup E, Doving KB, Winberg S. Differential effects of mercurial compounds on the electroolfactogram (EOG) of salmon (Salmo salar L.). Ecotoxicol Environ Saf 1990; 20(3):269-76.

Berntssen MH, Aatland A, Handy RD. Chronic dietary mercury exposure causes oxidative stress, brain lesions, and altered behaviour in Atlantic salmon (Salmo salar) parr. Aquat Toxicol 2003;65:55-72.

Boening DW. Ecological effects, transport, and fate of mercury: a general review. Chemosphere 2000;40(12):1335-51.

Burger J, Gochfeld M. Mercury in fish available in supermarkets in Illinois: are there regional differences. Sci Total Environ 2006;367:1010-6.

Canário J, Antunes P, Lavrado J, Vale C. Simple method for monomethylmercury determination in estuarine sediments. Trends Anal Chem 2004;23:10-1.

Coelho JP, Pereira ME, Duarte AC, Pardal MA. Macroalgae response to a mercury contamination gradient in a temperate antioxidant system breakdown in brain coastal lagoon (Ria de Aveiro, Portugal). Estuar Coast Shelf Sci 2005;65:492-500.

Conaway CH, Squire S, Mason RP, Flegal AR. Mercury speciation in the San Francisco Bay estuary. Mar Chem 2003;80:199-225.

Costley CT, Mossop KF, Dean JR, Garden LM, Marshall J, Carrol J. Determination of mercury in environmental and biological samples using pyrolysis atomic absorption spectrometry with gold amalgamation. Anal Chim Acta 2000;405:179-83.

Dove SG, Kingsford MJ. Use of otoliths and eye lenses for measuring trace-metal incorporation in fishes: a biogeographic study. Mar Biol 1998;130:377-87. 
Ercal N, Gurer-Orhan H, Aykin-Bums N. Toxic metals and oxidative stress part I: mechanisms involved in metal induced oxidative damage. Curr Top Med Chem 2001;1: 529-39.

Farina M, Avila DS, Rocha JBT, Aschner M. Metals, oxidative stress and neurodegeneration: a focus on iron, manganese and mercury. Neurochem Int 2013;62:575-94.

Guilherme S, Válega M, Pereira ME, Santos MA, Pacheco M. Antioxidant and biotransformation responses in Liza aurata under environmental mercury exposure - relationship with mercury accumulation and implications for public health. Mar Pollut Bull 2008;56:845-59.

Guzzi GP, Porta CAM. Molecular mechanisms triggered by mercury. Toxicology 2008; 244(1):1-12.

Korbas M, Blechinger SR, Krone PH, Pickering IJ, George GN. Localizing organomercury uptake and accumulation in zebrafish larvae at the tissue and cellular level. Proc Natl Acad Sci U S A 2008;105(34):12108-12.

Korbas M, Krone PH, Pickering IJ, George GN. Dynamic accumulation and redistribution of methylmercury in the lens of developing zebrafish embryos and larvae. J Biol Inorg Chem 2010;15:1137-45.

Korbas M, MacDonald TC, Pickering IJ, George GN, Krone PH. Chemical forms matters: differential accumulation of mercury following inorganic and organic mercury exposures in zebrafish larvae. ACS Chem Biol 2012;7:411-20.

Korbas M, Lai B, Vogt S, Gleber S-C, Karunakaran C, Pickering IJ, et al. Methylmercury targets photoreceptor outer segments. ACS Chem Biol 2013;8(10):2256-63.

Leaner JJ, Mason RP. Methylmercury uptake and distribution kinetics in sheepshead minnows, Cyprinodon variegatus, after exposure to $\mathrm{CH}_{3} \mathrm{Hg}$ spiked food. Environ Toxicol Chem 2004;23:2138-46.

Lemire M, Fillion M, Frenette B, Mayer A, Philibert A, Sousa Passos CS, et al. Selenium and mercury in the Brazilian Amazon: opposing influences on age-related cataracts. Environ Health Perspect 2010;118(11):1584-9.

Mieiro CL, Pacheco M, Pereira ME, Duarte AC. Mercury distribution in key tissues of fish (Liza aurata) inhabiting a contaminated estuary - implications for human and ecosystem health risk assessment. J Environ Monit 2009;11(5):1004-11.

Mieiro CL, Ahmad I, Pereira ME, Duarte AC, Pacheco M. Antioxidant system breakdown in brain of feral golden grey mullet (Liza aurata) as an effect of mercury exposure. Ecotoxicology 2010;19(6):1034-45.

Mieiro CL, Pereira ME, Duarte AC, Pacheco M. Brain as a critical target of mercury in environmentally exposed fish (Dicentrarchus labrax) - bioaccumulation and oxidative stress profiles. Aquat Toxicol 2011;103:233-40.

Oliveira Ribeiro CA, Rouleau C, Pelletier E, Audet C, Tjälve H. Distribution kinetics of dietary methylmercury in the Arctic charr (Salvelinus alpinus). Environ Sci Technol 2000;33:902-7.

Pereira E, Abreu SN, Coelho JP, Lopes CB, Pardal MA, Vale C, et al. Seasonal fluctuations of tissue mercury contents in the European shore crab Carcinus maenas from low and high contamination areas (Ria de Aveiro, Portugal). Mar Pollut Bull 2006;52:1450-7.
Pereira P, de Pablo H, Vale C, Pacheco M. Combined use of environmental data and biomarkers in fish (Liza aurata) inhabiting a eutrophic and metal-contaminated coastal system - gills reflect environmental contamination. Mar Environ Res 2010;69:53-62.

Pereira P, Raimundo J, Canário J, Almeida A, Pacheco M. Looking at the aquatic contamination through fish eyes - a faithful picture based on metals burden. Mar Pollut Bull 2013;77:375-9.

Raimundo J, Vale C, Canário J, Branco V, Moura I. Relations between mercury, methylmercury and selenium in tissues of Octopus vulgaris from the Portuguese Coast. Environ Pollut 2010;158:2094-100.

Ramalhosa E, Monterroso P, Abreu S, Pereira E, Vale C, Duarte AC. Storage and export of mercury from a contaminated bay (Ria de Aveiro, Portugal). Wetl Ecol Manag 2001;9:311-6.

Rouleau C, Borg-Neczak K, Gottofrey J, Tjälve H. Accumulation of waterborne mercury(II) in specific areas of fish brain. Environ Sci Technol 1999;33(19):3384-9.

Sokolova IM, Lannig G. Interactive effects of metal pollution and temperature on metabolism in aquatic ectotherms: implications of global climate change. Climate Res 2008; 37:181-201.

Stringari J, Nunes AKC, Franco JL, Bohrer D, Garcia SC, Dafre AL, et al. Prenatal methylmercury exposure hampers glutathione antioxidant system ontogenesis and causes long-lasting oxidative stress in the mouse brain. Toxicol Appl Pharmacol 2008;227: 405-11.

Trudel M, Rasmussen JB. Modeling the elimination of mercury by fish. Environ Sci Technol 1997;31(6):1716-22.

Tsui MTK, Wang WX. Uptake and elimination routes of inorganic mercury and methylmercury in Daphnia magna. Environ Sci Technol 2004;38(3):808-16.

U.S.EPA. Method 1631: methyl mercury in water by distillation, aqueous ethylation, purge and trap, and cold vapor atomic fluorescence spectrometry. Environmental Protection Agency: Washington, United States; 2001.

U.S.EPA. Method 1630: mercury in water by oxidation, purge and trap, and cold vapor atomic fluorescence spectrometry. Environmental Protection Agency: Washington, United States; 2002.

Van der Oost R, Beyer J, Vermeulen NPE. Fish bioaccumulation and biomarkers in environmental risk assessment: a review. Environ Toxicol Pharmacol 2003;13:57-149.

Westöö G. Determination of methylmercury compounds in foodstuffs. II. Determination of methylmercury in fish, egg, meat, and liver. Acta Chem Scand 1967;21: 1790-801.

Zhang Y, Adeloju SB. Speciation of mercury in fish samples by flow injection catalytic cold vapour atomic absorption spectrometry. Anal Chim Acta 2012;721:22-7.

Zheng W, Aschner M, Ghersi-Egea JF. Brain barrier systems: a new frontier in metal neurotoxicological research. Toxicol Appl Pharmacol 2003;192:1-11.

Zorita I, Ortiz-Zarragoitia M, Apraiz I, Cancio I, Orbea A, Soto M, et al. Assessment of biological effects of environmental pollution along the NW Mediterranean Sea using red mullets as sentinel organisms. Environ Pollut 2008;153:157-68. 